\title{
Visualization, imaging and new preclinical diagnostics in radiation oncology
}

\author{
Clemens C Cyran ${ }^{1 *}$, Philipp M Paprottka ${ }^{1}$, Michel Eisenblätter ${ }^{3,4}$, Dirk A Clevert ${ }^{1}$, Carsten Rist ${ }^{1}$, Konstantin Nikolaou ${ }^{1}$, \\ Kirsten Lauber ${ }^{2}$, Frederik Wenz ${ }^{5}$, Daniel Hausmann ${ }^{6}$, Maximilian F Reiser ${ }^{1}$, Claus Belka² and Maximilian Niyazi ${ }^{2}$
}

\begin{abstract}
Innovative strategies in cancer radiotherapy are stimulated by the growing knowledge on cellular and molecular tumor biology, tumor pathophysiology, and tumor microenvironment. In terms of tumor diagnostics and therapy monitoring, the reliable delineation of tumor boundaries and the assessment of tumor heterogeneity are increasingly complemented by the non-invasive characterization of functional and molecular processes, moving preclinical and clinical imaging from solely assessing tumor morphology towards the visualization of physiological and pathophysiological processes. Functional and molecular imaging techniques allow for the non-invasive characterization of tissues in vivo, using different modalities, including computed tomography (CT), magnetic resonance imaging $(\mathrm{MRI})$, ultrasound, positron emission tomography (PET) and optical imaging (OI). With novel therapeutic concepts combining optimized radiotherapy with molecularly targeted agents focusing on tumor cell proliferation, angiogenesis, and cell death, the non-invasive assessment of tumor microcirculation and tissue water diffusion, together with strategies for imaging the mechanisms of cellular injury and repair is of particular interest. Characterizing the tumor microenvironment prior to and in response to irradiation will help to optimize the outcome of radiotherapy. These novel concepts of personalized multi-modal cancer therapy require careful pre-treatment stratification as well as a timely and efficient therapy monitoring to maximize patient benefit on an individual basis. Functional and molecular imaging techniques are key in this regard to open novel opportunities for exploring and understanding the underlying mechanisms with the perspective to optimize therapeutic concepts and translate them into a personalized form of radiotherapy in the near future.
\end{abstract}

Keywords: Radiation oncology, Molecular imaging, Functional imaging, Preclinical models

\section{Introduction}

The effective use of radiation for cancer treatment is closely linked to the optimal application of imaging for staging and tumor characterization. Therefore any improvement in the field of imaging will impact on radiation oncology per se. In a broader sense the term imaging may not only be used to cover aspects of patho-anatomical imaging but may also cover all relevant aspects of additional functional visualization. The growing knowledge on the pathophysiology of cancer and the associated paradigm shift in therapeutic concepts are moving preclinical and clinical imaging from exclusively assessing tumor morphology towards the

\footnotetext{
* Correspondence: Clemens.Cyran@med.Imu.de

'Department of Clinical Radiology, Laboratory of Experimental Radiology, University of Munich Hospitals, Campus Großhadern, Marchioninistraße 15, 81377 Munich, Germany

Full list of author information is available at the end of the article
}

visualization of physiological and pathophysiological processes on a molecular level. Functional and molecular imaging allows for the non-invasive characterization of tissues in vivo, and comprises techniques, such as computed tomography $(\mathrm{CT})$, magnetic resonance imaging (MRI), ultrasound, positron emission tomography (PET) and optical imaging (OI). These novel imaging techniques have the potential for the visualization of functional tumor properties and the quantification of molecular pathways regulating the hallmarks of cancer [1]. As such, signaling pathways orchestrating proliferation, survival, angiogenesis, invasiveness, metastasis, and different types of cell death can be visualized either directly or indirectly via surrogate markers [2]. Imaging the mechanisms of cellular injury, repair, and cell death is of particular interest for characterizing the tumor microenvironment prior to and in response to

\section{Biomed Central}

(c) 2014 Cyran et al.; licensee BioMed Central Ltd. This is an open access article distributed under the terms of the Creative Commons Attribution License (http://creativecommons.org/licenses/by/2.0), which permits unrestricted use, distribution, and reproduction in any medium, provided the original work is properly cited. 
irradiation, and hence for optimizing the outcome of radiotherapy (RT) [3].

$\mathrm{RT}$ is an established, highly effective cancer treatment option applied for definite, curative treatment as well as for palliative care. Together with surgery and/or chemotherapy it is an integral part of multimodality approaches. Novel therapeutic concepts include optimized radiotherapy in combination with molecularly targeted agents focusing on tumor cell proliferation, angiogenesis, and cell death [4]. Importantly, these concepts require predictive biomarkers in order to stratify tumors for the appropriate therapy according to their individual molecular profile as well as biomarkers for monitoring the therapeutic outcome on a non-invasive and serial basis in vivo. E.g. with regard to tumor heterogeneity, the non-invasive evaluation of cellular tumor properties, such as proliferation, using molecular imaging methods could be of great interest for radiotherapy planning, for the identification of highly proliferative tumor areas. Functional and molecular imaging techniques may be key in this regard, since they open novel and exciting opportunities for exploring the molecular mechanisms in radiation biology with the possibility to optimize therapeutic concepts and translate them into a personalized form of radiotherapy in future.

\section{Imaging modalities}

\section{Computed Tomography (CT)}

$\mathrm{CT}$ is one of the leading imaging modalities in medical imaging and standard-of-care in RT planning. Advantages include short examination times allowing for whole body imaging within seconds, broad availability of the technique as well as low costs. Additionally, CT offers high spatial resolution at the submillimeter level. In small animal imaging, morphologic micro CT has shown significant potential with benefits, including high throughput and superior resolution. Winkelmann and colleagues investigated micro $\mathrm{CT}$ in a bone metastasis model of prostate cancer in mice and found that bone micro CT was able to non-invasively follow the onset and progression of bone metastatic lesions as small as $300 \mu \mathrm{m}$ in diameter [5]. Although radiation dose per micro CT scan approached 7-9 cGy, with six to nine micro CT examinations per mouse over a 7-week period, the applied radiation dose did not induce tumor stasis. However, the radiation dose applied by diagnostic micro CT has to be taken into account, particularly, when investigating micro CT for RT planning in small animal tumor models. A study by Boll and colleagues [6] investigated a dedicated alkaline earth metal-based nanoparticulate contrast agent for micro CT imaging of liver metastases in a colon carcinoma metastasis model in mice and reported that liver metastases as small as $300 \mu \mathrm{m}$ were detectable after a single injection. The authors concluded that the investigated nanoparticulate contrast agent is suitable to compensate for the limited soft tissue contrast of unenhanced micro CT and allows for high resolution and high soft tissue contrast imaging of tumors in small animal models. Therefore, micro CT enhanced with dedicated contrast media may be of particular interest for the delineation and non-invasive characterization of tumors before and during radiotherapy in the preclinical setting.

Recent studies also support the value of perfusion CT as a functional imaging method in oncology [7]. Perfusion imaging techniques based on CT, MRI and ultrasound have been applied for the non-invasive quantification of functional parameters of tissue microcirculation [8-11]. It has also been shown that dynamic contrast-enhanced CT (DCE-CT) allows for the assessment of pathologically increased tissue perfusion, blood volume and permeability [12], reflecting typical features of angiogenically active tissues, such as tumors. Surrogate parameters of tumor microcirculation assessed by DCE-CT have the potential to predict response to chemotherapy or irradiation in various cancers, e.g. cancers of the head and neck, lung, and rectum [13-15]. In anti-angiogenic tumor therapy, DCE-CT has shown its applicability for early assessment of the therapeutic effect on tumor vascularization, identifying treatment responders from non-responders, and optimizing personalized molecular therapies on an individualized patient basis.

Dual-energy CT (DECT) offers high soft tissue contrast and a clear differentiation between soft tissue, iodine contrast and bone. Dual source DECT can provide iodine maps which reflect iodine content in a tissue of interest and which have been demonstrated to show good correspondence to perfusion images in the lung and heart $[16,17]$. In an experimental study of a VX2rabbit model of liver cancer Zhang and colleagues reported that DECT iodine maps correlated well with multiparametric perfusion CT measurements for monitoring tumor angiogenesis with a significantly lower effective radiation dose. It was concluded that DECT might have the potential for serially monitoring angiogenesis in solid tumors with a significant reduction in radiation dose compared to perfusion CT techniques [18]. This technique may be of particular interest for serially monitoring tumor heterogeneity and angiogenesis in the planning and monitoring of RT combined with anti-angiogenic agents.

\section{Magnetic Resonance Imaging (MRI)}

Based on strong magnetic fields (clinically between 1.5 and 3 Tesla, human research scanners up to 7 Tesla) MRI is able to provide superior soft tissue contrast and high spatial resolution without the application of ionizing radiation. Besides its morphologic capabilities useful for clinical staging and RT planning purposes $[19,20]$, MRI is increasingly developed for functional and molecular imaging methods, 
among them perfusion and diffusion imaging as well as MR spectroscopy and molecular MRI. Perfusion MRI can be applied to quantify functional parameters of tissue microcirculation, which have been shown to reflect tissue properties such as vitality, angiogenesis and proliferation [21]. Novel imaging methods such as ${ }^{23}$ Natrium MRI have been proposed as a potential imaging biomarker for the assessment of tumor viability and the evaluation of therapy response in cancer patients [22].

\section{Magnetic Resonance Proton Spectroscopy (MRS)}

MR spectroscopy uses selective radiofrequency pulses for the investigation of the molecular composition of tissues [23,24]. The Fourier transformation of the acquired signal generates a defined spectrum allowing for the discrimination of different metabolites in the investigated tissue, which may be pathognomonic for certain underlying pathologies. Metabolites detected in tumor tissues include choline-containing compounds, creatine, glutamate, lactate, $\mathrm{N}$-acetyl aspartate (NAA), myoinositol (mI) and taurine [25]. The concentration of each of these metabolites can be mapped on spectroscopic images with a voxel size of $0.7-1 \mathrm{~cm}^{3}$. NAA is predominantly a neuronal marker and decreases associated with neuronal damage and dysfunction [25]. Choline is associated with cell membrane synthesis as well as increased metabolic turnover and is elevated in tumors and inflammatory processes [25]. Creatine has been shown to be a marker of energy metabolism in the brain [26], while $\mathrm{mI}$ was confirmed as a glial cell marker and has been used as an indicator of myelin breakdown [27]. In glioblastomas increased levels of creatine and choline as well as a lowered level of $\mathrm{N}$-acetyl aspartate were found [28]. Additionally, MRS can be applied for pre-operative staging of gliomas [29] and for monitoring tissue $\mathrm{pH}$ and temperature [30]. With regard to radiation therapy, MRS may be a sensitive tool for monitoring radiationinduced changes in tumors based on the acquired spectrum of metabolites. MRS has also been postulated to be of particular interest in focal dose escalation in prostate cancer patients [31]. Significant technical challenges for clinical translation remain particularly with regard to reproducibility in the quantification of chemical metabolites in tumors as well as impeded data quality due to local-field inhomogeneities caused by healthy tissue adjacent to the tumor [26].

\section{MR perfusion}

MR perfusion represents one of the most promising methods of functional MR imaging. Perfusion imaging is defined as the in vivo assessment and quantification of microcirculatory parameters in different tissues, which may allow for the characterization of an underlying pathology. Depending on the imaging protocol and kinetic models applied for data analysis different parameters of microcirculation, such as plasma flow, extraction fraction, or relative plasma volume, can be assessed reflecting tissue properties, such as tissue perfusion, endothelial permeability, and tissue vascularity [32], in vivo. Technically, MR perfusion imaging can be performed by dynamic contrast-enhanced imaging (DCE), dynamic susceptibility contrast imaging (DSC), and arterial spin labeling (ASL) techniques. The most common method for perfusion imaging, however, is dynamic contrast-enhanced imaging.

Methodologically, DCE imaging monitors signal enhancement before, during and after intravenous injection of a paramagnetic contrast agent applying T1-weighted sequences with high temporal and spatial resolution [21]. The resulting signal-intensity vs. time curve can be analyzed to yield different quantitative and semiquantitative parameters, for example maximum signal enhancement, time-to-peak, maximum slope or area under the curve. These semi-quantitative parameters describe important aspects of contrast media kinetics and can be routinely assessed with high robustness. However, physiological interpretation of these semi-quantitative parameters is often difficult [33] and factors like acquisition time, temporal resolution, sequence parameters, contrast media dose, and bolus velocity greatly influence semi-quantitative parameters. As a consequence, semiquantitative parameters are only of limited use for follow-up measurements and multicenter studies. As demonstrated in Figure 1, DCE-MRI can also be applied for the assessment of quantitative parameters of tissue microcirculation, such as plasma flow $(\mathrm{ml} / \mathrm{min} / 100 \mathrm{ml})$, extraction flow $(\mathrm{ml} / \mathrm{min} / 100 \mathrm{ml})$, and plasma volume (\%) [34]. These parameters are considered to be physiologically distinct with better suitability for longitudinal and multicenter studies, but strongly depend on standardized imaging and analysis protocols. Depending on the kinetic profile of the contrast medium, investigated tissue of interest and acquisition technique a range of kinetic models is available for the analysis of the kinetic data, e.g. the Patlak or the Tofts model [35]. The best model to fit the data can be evaluated using the Akaike's information criterion, which can be applied to support model selection for the mathematical description of tracer kinetics [36]. Clinically, MR perfusion imaging has great potential as a functional imaging method in oncology for the assessment of tumor vitality, angiogenesis, and tumor heterogeneity. In e.g. prostate cancer, it can be used after radical prostatectomy to detect local recurrence without an endorectal coil [37], for therapy response imaging [38] as well as for the determination of extracapsular extension [39]. However, standardization of acquisition protocols and data analysis remain major obstacles towards broader establishment of the technique in clinical routine [21]. 


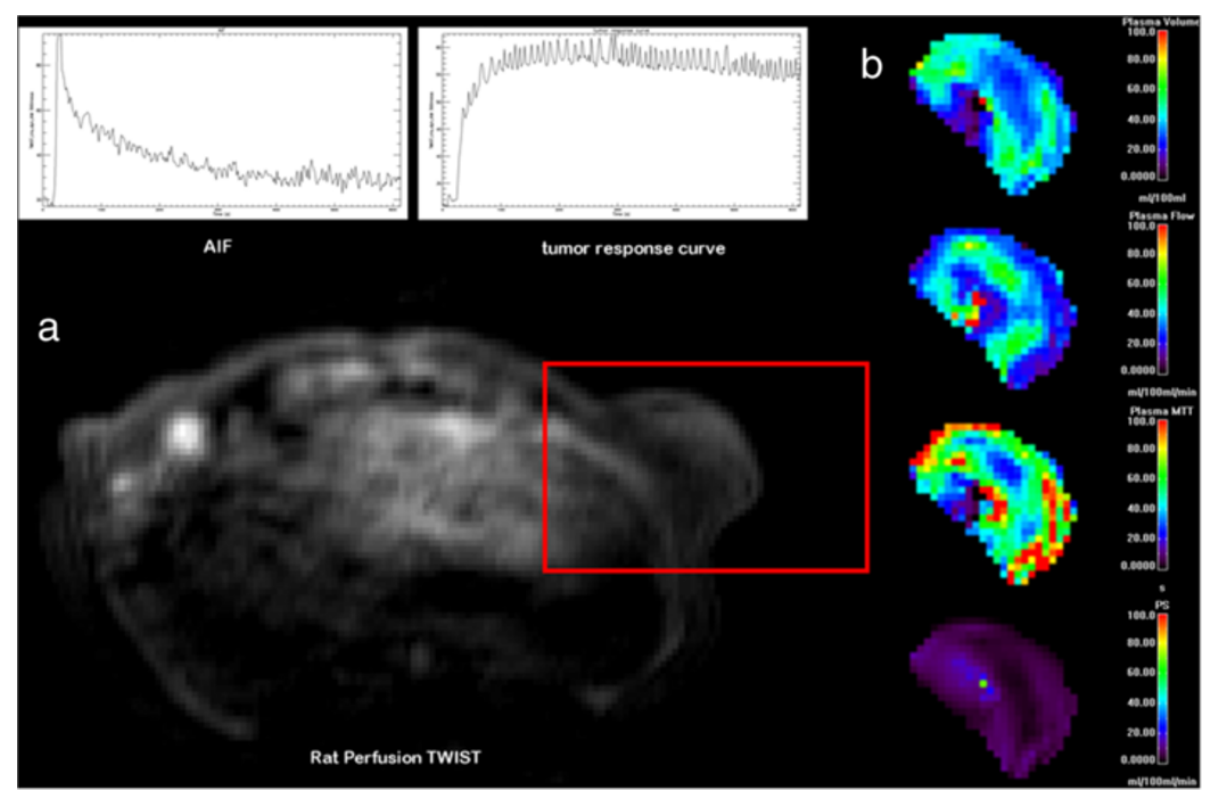

Figure 1 Representative axial T1 weighted TWIST image of an athymic rat bearing a subcutaneous colon carcinoma xenograft over the left flank. (a) Representative axial T1 weighted TWIST image of an athymic rat bearing a subcutaneous colon carcinoma xenograft over the left flank with the arterial input function (AIF) measured in the inferior vena cava as well as the signal enhancement curve over the tumor. (b) Representative quantitative parameter maps depicting different parameters of tumor microcirculation (from top to bottom): plasma volume (\%), plasma flow $(\mathrm{ml} / 100 \mathrm{ml} / \mathrm{min})$, plasma mean transit time $(\mathrm{s})$, permeability surface area product $(\mathrm{ml} / 100 \mathrm{ml} / \mathrm{min})$.

\section{MR diffusion}

MR diffusion imaging is another major technique of functional MR imaging and is already routinely applied in neuroradiologic imaging protocols. In MR diffusion imaging, gradient pulses generate a spatially varying magnetic field with resulting phase differences of the MR signal, which are caused by the random motion of water molecules in the tissue (Brownian motion). Diagnostic applications of MR diffusion imaging include ischemia [40], tumor diagnosis and characterization [41], multiple sclerosis [42], therapy response assessment [38] as well as fiber tracking using diffusion tensor imaging (DTI). Recent studies have also investigated the potential of diffusion imaging for therapy monitoring [43] and the assessment of biomarkers in oncology with promising results [41]. In this context, Somford and colleagues successfully investigated DWI for the identification of high-grade prostate carcinoma in patients with a Gleason score $\geq 3+3=6$ after TRUS-guided biopsy and concluded that DWI is able to predict the presence of highgrade tumor with significant relevance for subsequent treatment decisions. In a study of 73 patients with prostate cancer, Ueno et al. found that diffusion-weighted MRI with ultra high $b$-values $(b=2000 \mathrm{~s} / \mathrm{mm})$ is superior compared to the use of high $b$-values $(b=1000 \mathrm{~s} / \mathrm{mm})$ for prostate cancer detection, validated by histopathology following radical prostatectomy [44]. These ultra-high b-values may be assessable by computed DW MRI, as shown in a study by Blackledge and co-workers, who investigated DW MR imaging in 10 oncologic patients with $\mathrm{b}$ values of 0 and
$900 \mathrm{sec} / \mathrm{mm}$, subsequently generating images with computed $b$ values of 1500 and $2000 \mathrm{sec} / \mathrm{mm}$. They found that images with a computed b value of $2000 \mathrm{sec} / \mathrm{mm}$ resulted in higher overall diagnostic sensitivity and specificity compared to images with an acquired b value of $900 \mathrm{sec} / \mathrm{mm}$ [45]. A novel application of MR diffusion is intravoxel incoherent motion (IVIM) imaging, which allows to derive quantitative parameters that reflect tissue microcapillary perfusion and tissue diffusivity [46]. A bi-exponential model is fitted to diffusion-weighted data, to quantify the measured signal attenuation as a function of diffusion (b-value). Perfusion information is extracted from the initial signal attenuation at low b-values between 0 and ca. $150 \mathrm{~s} / \mathrm{mm}^{3}$ [46]. Figure 2 shows a representative example of a subcutaneous tumor xenograft of head and neck squamous cell carcinoma in rats imaged by diffusion-weighted MRI with voxel-wise analysis using the bi-exponential IVIM model.

Several recent studies have also discussed a possibly enhanced diagnostic value of multiparametric MRI combining morphologic and functional information from perfusion and diffusion parameters for the noninvasive characterization and differentiation of tumors [47]. The recently published guidelines of the European Society of Urogenital Radiology (ESUR) describe the application of multiparametric MRI for the detection and staging of prostate cancer, a separate protocol for node and bone imaging as well as a standardized reporting system (PI-RADS), analogue to breast imaging [48]. 


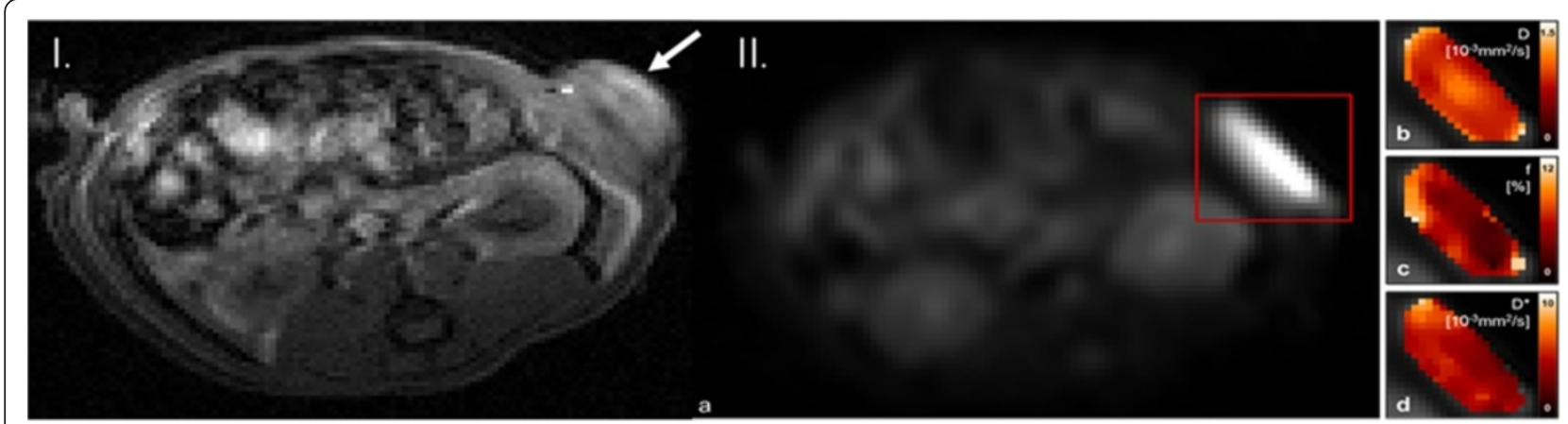

Figure 2 Representative morphological and diffusion-weighted images of an athymic rat bearing a subcutaneous HNSCC (head and neck squamous cell carcinoma) over the left lateral flank. (I.) T1-weighted flash 3D morphological image of an athymic rat bearing a subcutaneous HNSCC (head and neck squamous cell carcinoma) over the left lateral flank for anatomical correlation (white arrow). (II.) Example of a voxel-wise analysis of diffusion weighted images using the bi-exponential IVIM-model. Initial T2-weighted image is shown in (a), (b)-(c) depict the calculated parameter maps for tissue diffusivity $D(\mathbf{b})$, perfusion fraction $f(\mathbf{c})$ and pseudo diffusivity $D^{*}(\mathbf{d})$. Reduced values for $f$ towards the center of the tumor indicate a local decrease in perfusion.

\section{Molecular MRI (mMRI)}

mMRI applies targeted, gadolinium- or iron-based contrast agents of different designs, which allow for the dedicated depiction of molecular processes in vivo using antibodies, peptides or peptidomimetics [49,50]. Based on Gadolinium (Gd) or iron, these contrast agents cause a shortening of the $\mathrm{T} 1-(\mathrm{Gd})$ or the $\mathrm{T} 2 / \mathrm{T} 2 *$ time (iron) and lead to a change in tissue contrast. To achieve highly specific binding properties, Gd-chelates or nanoparticles are conjugated to antibodies, peptides or peptidomimetics for the dedicated in vivo visualization of molecular processes [50]. Serres and co-workers developed a targeted MRI contrast agent based on iron oxides that enables imaging of endothelial vascular cell adhesion molecule-1 (VCAM-1), which is known to be upregulated on vessels of cerebral metastases [51]. They investigated whether MRI enhanced with the targeted anti-VCAM-1 microparticles of iron oxide (anti-VCAM1 MPIO) would be able to depict up-regulated VCAM-1 in a model of human breast carcinoma cerebral metastasis in mice and if early detection of these metastases would be feasible. The results indicated that by use of the VCAM-1 targeted MRI contrast agent, it is possible to detect brain metastases substantially earlier than with the established gadolinium-based small molecular contrast media and concluded that this approach represents a highly sensitive method for the early detection of brain metastases with the potential for clinical translation [51]. Recently, enzymatic reporter systems for the noninvasive investigation of gene expression patterns detectable by MRI have been investigated combining the relatively high spatial and temporal resolution of MRI with the ability of each genetically-expressed enzyme to generate many MRI-detectable product molecules [52]. Currently, most of these molecular MR contrast agents are experimental and not approved for human use.
Particularly concerns of potential immunogenicity and incomplete bio-elimination of targeted $\mathrm{MR}$ contrast agents hamper clinical translation.

\section{Hyperpolarized MRS}

Compared to the currently established proton-based MR imaging, other nuclei like ${ }^{3} \mathrm{He},{ }^{129} \mathrm{Xe}$ or ${ }^{13} \mathrm{C}$ have lower occurrence in the human body. If these alternative nuclei were used for the generation of the radiofrequency signal in MRI, the resulting signal-to-noise ratio (SNR) would be quite low. By means of hyperpolarization, however, it is possible to excite specific nuclei, thereby potentiating their MR signal to achieve a better SNR. ${ }^{3} \mathrm{He}$ und ${ }^{129} \mathrm{Xe}$ can be polarized by optical pumping, while ${ }^{13} \mathrm{C}$ can be polarized using parahydrogen and dynamic polarization [53]. Different studies have investigated ${ }^{13} \mathrm{C}$ in MR angiography- und perfusion studies as well as ${ }^{129} \mathrm{Xe}$ for lung imaging $[54,55]$. Experimental, hyperpolarized MR contrast agents such as ${ }^{13} \mathrm{C}$-urea do not alter relaxation time, as established $\mathrm{Gd}$ - or iron based $\mathrm{MR}$ contrast media, but resemble in their function radioactive tracers, with the hyperpolarized nuclei representing the basis for the MR signal.

To date, ${ }^{13} \mathrm{C}$ pyruvate has been the most widely used hyperpolarized substrate for MRS, which has also been applied for tumor response monitoring [56], and was the first to be used in a clinical trial of the technique [57]. In a study investigating the effects of the mTOR inhibitor everolimus on a highly invasive orthotopic glioblastoma model in rats. Chaumeil and colleagues demonstrated that hyperpolarized ${ }^{13} \mathrm{C}$ MRS can be used on a clinical MR system to monitor early metabolic response by means of measurement of the HP lactate-to-pyruvate ratios [58]. Similarly, Day et al. showed the applicability of hyperpolarized ${ }^{13} \mathrm{C}$ pyruvate MRS for the detection of treatment response $72 \mathrm{~h}$ following a whole brain 
irradiation with $15 \mathrm{~Gy}$ in a rat glioma model [59]. Golman and colleagues investigated ${ }^{13} \mathrm{C}$ pyruvate in P22 tumors in rats for the non-invasive imaging of the anaerobic glycolysis of the injected pyruvate to alanine and lactate, analogue to imaging of aerobic glycolysis with ${ }^{18}$ F-FDG-PET [60]. Further perspectives of hyperpolarized MRI were discussed in a paper of Mansson et al. who were able to show that the signal of ${ }^{13} \mathrm{C}$ nuclei varies depending on the hosting molecule, which could allow for refined discrimination of different ${ }^{13} \mathrm{C}$ containing molecules. This could be an advantage over radionuclide-based imaging modalities such as PET and SPECT [61]. Main problems of the still experimental hyperpolarization MRI include the very high costs as well as the rapid decline of the hyperpolarization, which allow only for a very short interval between application and imaging [62].

\section{Ultrasound}

In recent years, ultrasound has undergone significant technological advancement with an evolution from a simple morphology-based gray-scale image to a multiparametric high-resolution real-time imaging system. Major developments include the introduction of functional imaging options including sophisticated Doppler ultrasound, contrast-enhanced ultrasound (CEUS), and elastography for the non-invasive characterization of tissues with significantly improved spatial and temporal resolution. The development of gas-filled blood-pool microbubble contrast agents has significantly enhanced clinical and pre-clinical research applications with particular regard to the in vivo characterization of tissue microcirculation in a semi-quantitative and quantitative manner [63]. Novel targeted microbubble contrast agents available for research purposes open the door for a molecular evaluation of tissues, e.g. by selectively binding to vascular endothelial growth factor receptor (VEGFR-2) [64-68] and a possible theranostics application linked to high intensity focused ultrasound (HIFU) which may be used in recurrent prostate cancer [69] and the microbubble-assisted delivery of drugs and genes [70].

Clinically, in recent years image-guided radiotherapy has been a major issue in research and development for (mageguided radiotherapy (IGRT) and may be regarded as standard-of-care, especially in high-precision radiotherapy. One newly developed system is based on ultrasound - the Clarity 3D ${ }^{\text {th }}$ ultrasound system (Elekta, Stockholm, Sweden) is designed to track exemplarily the prostatic gland and adjacent organs-at-risk in order to minimize setup errors caused by organ motion, displacements and different filling states [71]. Furthermore, ultrasound has great potential to be established as a sensor for intrafractional movement as the tumor or organ motion can be tracked online as compared to a static cone beam CT (pre or post application of the individual fraction), e.g. in liver cancer/metastases or prostate cancer [72]. This in turn allows for an early detection of significant deviations and could in principle be used for real tumor tracking during irradiation.

\section{Contrast-enhanced sonography (CEUS)}

In CEUS, gas-filled microbubbles are injected intravenously, thereby creating a multitude of small interfaces with high echogenicity. After destruction, the gas (e.g. $\mathrm{SF}_{6}$ ) is eliminated over the lungs within minutes and phospholipid membranes will be endogenously metabolized. The diameter of most microbubbles ranges between 2-10 $\mu \mathrm{m}$, quite similar to the diameter of erythrocytes. Contrary to conventional small molecular CT- and MRI- contrast media, the microbubbles do not extravasate into the interstitial space, remain intravascular and therefore belong to the class of blood pool contrast media [73,74]. Microbubbles oscillate and vibrate resulting in a continuous improvement of gray scale contrast. With the development of high-frequency linear ultrasound transducers $(>20 \mathrm{MHz})$ ever-smaller structures can be examined by CEUS with superior temporal and spatial resolution (Figure 3).

For the most part CEUS has been applied for investigations of tumors in parenchymatous organs and in pathologies of the vascular system [75-83], where CEUS can be applied as a functional imaging method for the assessment of tissue microcirculation in healthy and malignant tissues. CEUS perfusion imaging may be particularly attractive for monitoring novel, molecular therapies in oncology mainly targeting tumor angiogenesis [84]. Paprottka and co-workers showed in an experimental study that CEUS allows for superior assessment of tumor perfusion compared to color-coded duplex ultrasound and power Doppler [84]. Other preclinical studies demonstrated that parameters of tumor microcirculation assessed by CEUS may be applicable as imaging biomarkers of tumor angiogenic activity and may have the potential to be used as non-invasive biomarkers of tumor responses under anti-angiogenic therapy (Figure 4) $[85,86]$. Radiotherapeutic applications of CEUS include treatment guidance in prostate brachytherapy planning [87] and it has a potential role in monitoring of liver metastases after stereotactic radiosurgery [88].

Apart from non-targeted, blood-pool ultrasound contrast media, targeted microbubbles have been developed as a molecular imaging technique by attaching specific ligands to the coating of gas-filled microbubbles. These targeted microbubbles can be applied for the non-invasive characterization of molecular tissue properties in vivo. As ultrasound microbubble contrast media remains intravascularly after intravenous injection, molecular targets have to be located on the luminal surface of vascular 


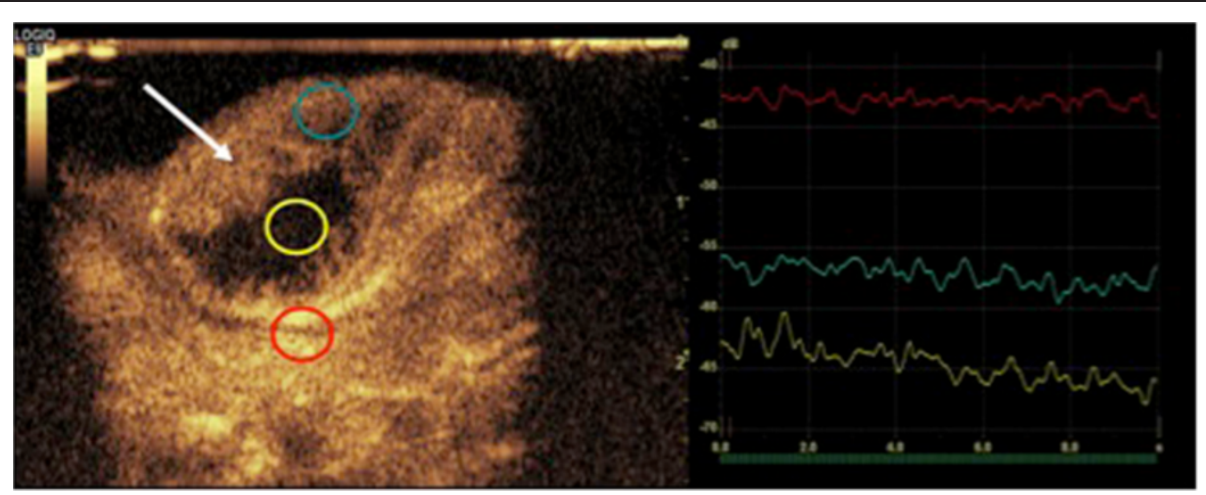

Figure 3 Contrast-enhanced ultrasound (CEUS) with intravascular $\mathrm{SF}_{6}$-filled microbubbles: online quantification of hypervascular tumor tissue (turquoise ROI), tumor necrosis (yellow ROI) and feeding vessels (red ROI).

endothelium. Targeted microbubbles have been conjugated to ligands specific for highly expressed molecular markers of tumor angiogenesis such as VEGFR-2 and $\alpha_{v} \beta_{3}$-integrin $[64,65,68,70]$ to allow for the assessment of tumor angiogenic activity and for monitoring anti-angiogenic therapies in preclinical tumor models [90-92]. Together with potential application in theranostics multiparametric, contrastenhanced ultrasound has developed to a high-potential tool for research and patient care combining high sensitivity, real-time morphological imaging, with functional and molecular imaging options with a lack of ionizing radiation and at comparably low costs [93].

\section{Elastography}

Tissue elastography complements the conventional Bimage, color Doppler, and CEUS in the assessment of pathologies $[94,95]$. Ultrasound elastography bridges the gap between modern state-of-the-art ultrasound and one of the most ancient examination techniques in medicine palpation. Tissue elasticity is frequently altered in the presence of inflammation or malignancy and can be detected by compression elastography on the basis of compression and release [96]. Malignancies frequently exhibit higher tissue stiffness due to high rates of cell proliferation and densely packed cells. Thus, they appear

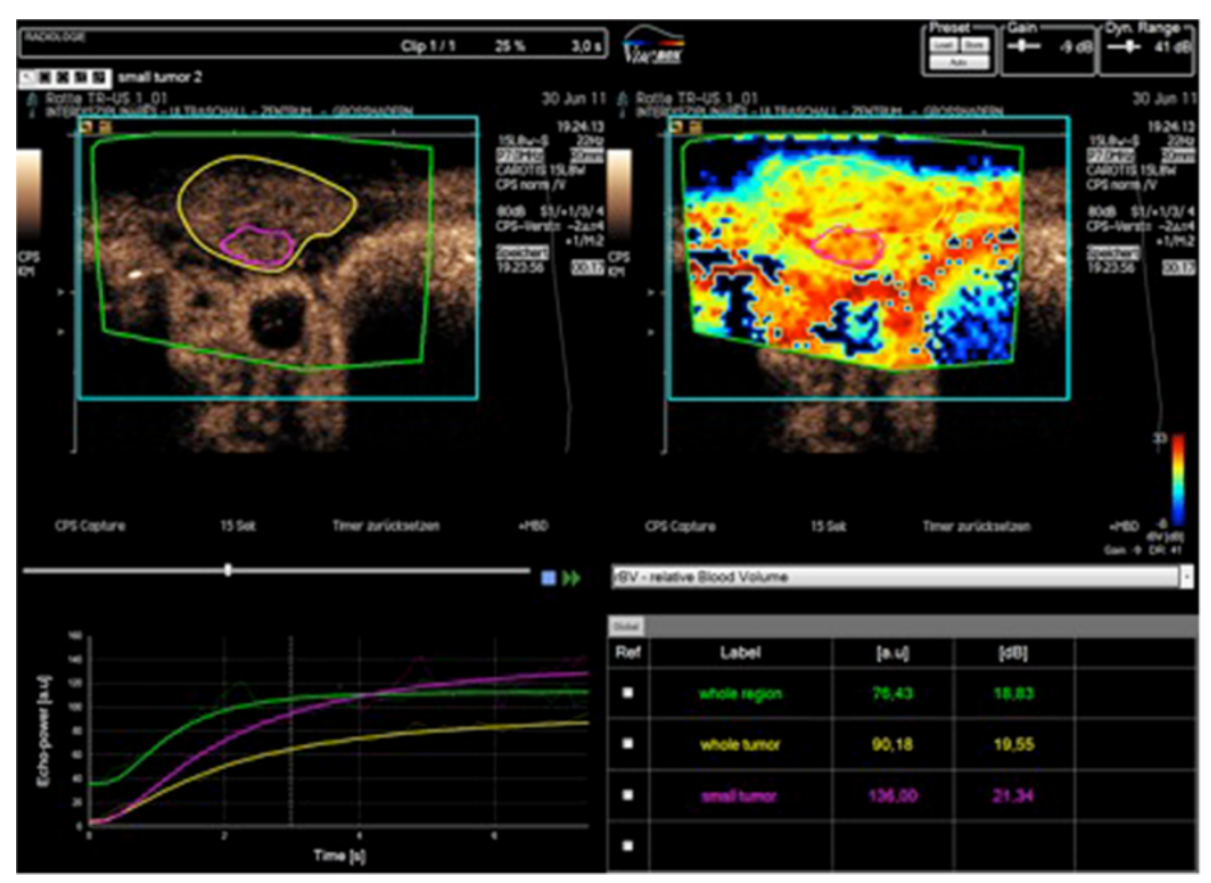

Figure 4 Offline absolute quantification of perfusion of the whole tumor and hypervascular tumor parts using the flash replenishment method [89]. ROls can be drawn in different parameter maps, allowing a simpler and more standardized analysis of the digitally stored video sequences. 
less elastic in ultrasound elastography. By means of the combined autocorrelation method, elastic tissue properties of different tissues can be assessed (Figure 5). Application of light pressure on the tissue with the ultrasound probe and the subsequent release aid to assess relative stiffness of the investigated tissue and differences can be visualized, either in gray scale or color coded, parallel, or merged with a conventional b-image (Figure 6). Several studies investigated ultrasound elastography in mammography as well as in liver and prostate imaging and found that elastic tissue properties contribute valuable information, which is not discriminable in conventional ultrasound [97-101]. In an animal study elastography was applied to monitor ethanol injections for the treatment of liver tumors, and the authors concluded that elastography added significant information compared to the conventional b-image [102,103]. After adjuvant radiotherapy of breast cancer, elastography can be used to quantify the extent of lymph edema [104].

\section{Optical imaging}

Optical imaging employs light for the assessment of functional and molecular tissue information. This light can either originate from administered, elicited fluorescent tracers or - as bioluminescence - from genetically modified cells [105]. Upon excitation with externally applied light of the proper wavelength, fluorescent tracers emit light with a higher wavelength that can be detected by a CCD (charged-coupled device) camera. Different forms of tracers have been described. For visualization of blood flow, unspecific, blood-flow distributing agents can be used, much resembling established contrast agents for $\mathrm{x}$-ray computed tomography or magnetic resonance tomography [106]. For visualization of molecular processes, targeted probes have been designed, typically consisting of a fluorescent dye (e.g. Cy 5.5) and a

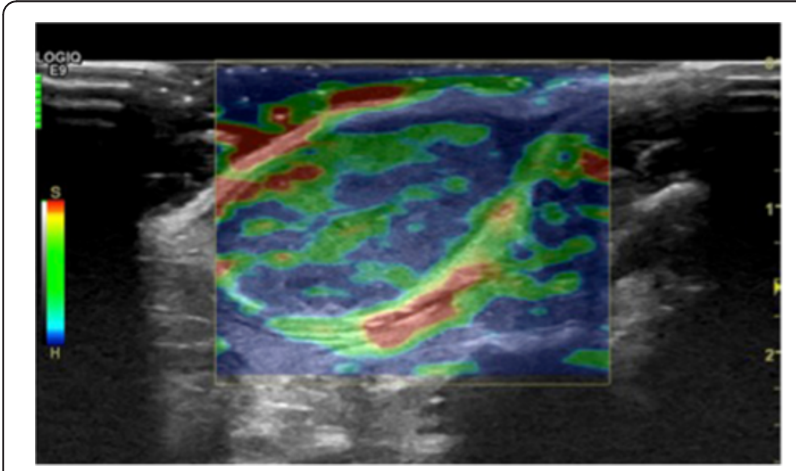

Figure 5 Ultrasound elastography (blue: hard tissue, green: soft tissue): Central tumor necrosis is encoded in green. Due to the immediate vicinity of subcutaneous tissues to the transducer, subcutaneous tumor parts under compression are also coded in green. Further developments investigate elastography without manual compression to minimize these artifacts.

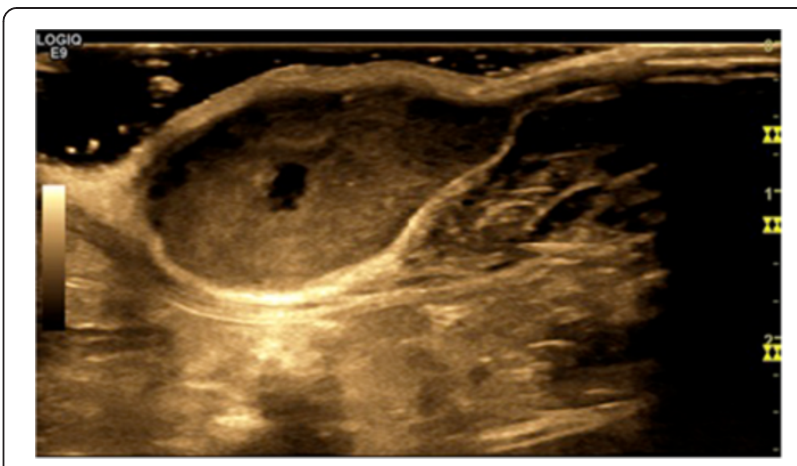

Figure 6 Gray-scale ultrasound for the evaluation of tumor heterogeneity. The extent of central tumor necrosis is significantly underestimated by gray-scale ultrasound compared to elastography.

binding moiety - e.g. an antibody or smaller peptide with binding specificity for the target of interest. To minimize tissue absorption and scattering of the emitted light, the optimal spectral range for in vivo applications has been defined as the near-infrared optical window (wavelengths 650-900 nm), with lowest tissue absorbance for hemoglobin, water and lipids. In bioluminescence, an in vivo enzymatic reaction is responsible for the emission of light. The most common enzymatic tool is the firefly luciferase system, where $D$-luciferine is oxidized using ATP (adenosine-tri-phosphate) and oxygen in a two-step mechanism. The resulting emission of yellow-green light at $575 \mathrm{~nm}$ can be employed to visualize luciferase-expressing cells in vivo following intravascular injection of D-luciferine, the substrate of firefly luciferase, or after providing D-luciferine in the drinking water. Advantages of bioluminescence imaging include (1) an exquisite imaging sensitivity due to a high signal-to-noise ratio caused by the lack of bioluminescence background signal (in mammals) and (2) the luciferase system does not require excitation light from outside to be activated. Disadvantages include the need for cell transfection with the luciferase reporter genes, substrate injection ( $D$-luciferine), and the poor spatial resolution of bioluminescence imaging compared to tracer-mediated fluorescence optical imaging. In recent years, many studies have investigated the luciferase bioluminescence assay to visualize a wide array of molecular pathways for the non-invasive characterization of the tumor microenvironment as useful tools in radiation and cancer biology research.

Bioluminescence optical imaging using firefly luciferase has been applied to image an array of biological pathways and cellular processes relevant for novel approaches in radiation and molecular cancer therapy [107]. In a recent study, Li and colleagues developed an imaging system for non-invasive quantification of epidermal growth factor receptor (EGFR) activation in vivo 
based on the bi-fragment luciferase reconstitution system. Epidermal growth factor and its receptor are part of a key-signaling cascade responsible for the initiation and growth of malignancies. Li and colleagues fused the EGF receptor and its interacting partner proteins growth factor receptor binding protein 2 (grb2), and Src homology 2 domain-containing protein (shc) to the aminoterminal and the carboxyterminal fragments of the firefly luciferase, respectively. In this system, firefly luciferase is only enzymatically active when the two parts of the protein are brought together, hence when EGFR, and grb2 or EGFR and shc are interacting and the signaling cascade is active. With the help of this system EGFinduced as well as radiation-induced pathway activation could be convincingly measured in vitro and in vivo (Figure 7) [108]. Moreover, this system was employed to visualize hyperthermia-induced EGFR activation in tumor cells and the potential mechanisms involved [109]. In an analogue study, Li and colleagues utilized their split-luciferase system in order to quantitatively assess DNA double strand breaks and their repair [110]. They fused the $\mathrm{N}$ - and C-terminal fragments of firefly luciferase with $\mathrm{H} 2 \mathrm{AX}$ and MDC1, two proteins, which at the sites of DNA double strand breaks physically interact with each other. Hence, upon generation of DNA double strand breaks, the two luciferase fragments are brought together and luciferase activity can be detected at the site of damage. Since DNA double strand breaks and the mechanisms of their repair are of crucial interest in the context of ionizing radiation, this imaging system is of specific relevance for monitoring the effect of radiotherapy in tumor tissue.

The study of Backer and colleagues exemplary illustrates strengths and drawbacks of targeted optical imaging with near-infrared fluorescent tracers. Human vascular endothelial growth factor (VEGF) was labeled with the fluorescent dye Cy5.5 (emission maximum $696 \mathrm{~nm}$ ) for application in an in vivo tumor model [111]. The elevated contrast, observed in the tumor following tracer administration was assigned to elevated VEGFR expression on tumor cells and adjacent endothelia. Unfortunately, the question remained unanswered, how specific this accumulation was. The authors missed to provide data on essential parameters, including whole
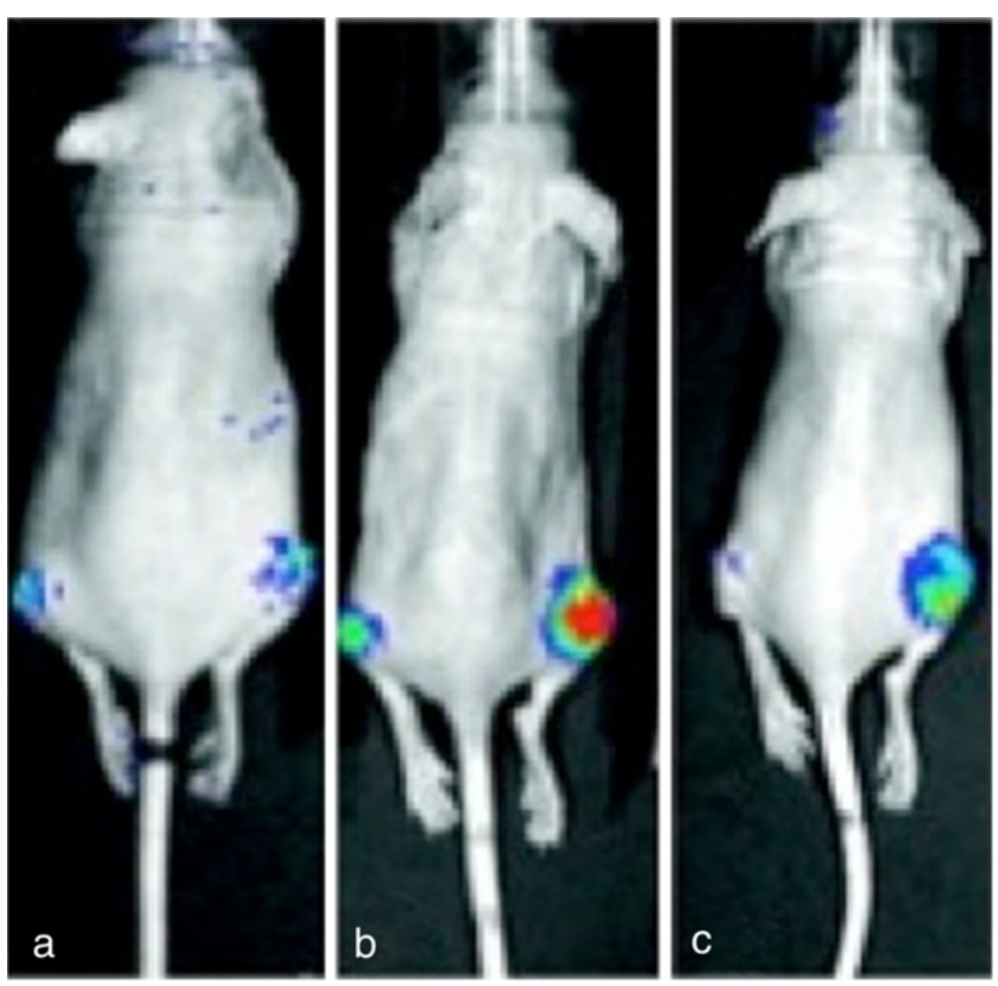

Figure 7 Mice implanted with EGFR-luc transfected H322 tumors over the right flank. EGFR activation during radiotherapy (B, C; 3x6Gy) induces consecutive Luciferase expression and thus detectable bioluminescence upon luciferine injection. Mice implanted into the right flank with EGFR-luc transfected H322 tumors. EGFR activation during radiotherapy (B, C; 3x6Gy) induces consecutive Luciferase expression and thus detectable Bioluminescence upon Luciferine injection. Changes to the EGFR activation by EGFR inhibition with e.g. Gefitinib (C) result in detectable alterations of the signal. Non-treated tumors (A) do not exhibit a specific signal. Adapted by permission from the American Association for Cancer Research: Li et al., Noninvasive imaging and quantification of epidermal growth factor receptor kinase activation in vivo. Cancer Research, 2008, 68, 4990-7. [109]. 
body distribution of the tracer or an unspecific control of equal size and distribution. Importantly, biodistribution studies and blocking experiments are a crucial requirement for such imaging studies in order to convincingly show that tracer-mediated fluorescence in fact is a reliable measure of tracer to target binding.

Mostly due to restricted penetration depth of light and strong scatter, clinical translation of optical imaging techniques seems to be limited to lesions in or close to the skin, lesions accessible by endoscopy (e.g. colon polyps), or intraoperative applications. To solve some of these limitations, current technical developments in optical imaging focus on scanners with improved penetration depth and sensitivity, including photoacoustic imaging systems as well as hybrid fluorescence molecular tomography $\mathrm{x}$-ray computed tomography scanners (FMT-XCT) [112-114]. The application of either or both technologies will help to provide significant insights into the molecular mechanisms of radiation and tumor biology in vivo. However, even state of the art optical imaging is a valuable modality for preclinical imaging in small animals, allowing for the non-invasive characterization of cells and tissues on a molecular level. The use of highly specific tracers or reporter gene-based bioluminescence imaging systems will help to gain a better understanding of the molecular processes, which take place in tumors in response to irradiation and/or targeted therapy, and will finally result in a more efficient pretherapeutic stratification of tumors for multimodal therapy.

\section{Positron emission tomography (PET)/single photon emission computed tomography (SPECT)}

PET is a non-invasive imaging technique that visualizes the distribution and accumulation of positron-emitting tracers in the whole body with high sensitivity providing functional and molecular information on tissues. With its high sensitivity for radiotracers even in picomolar amounts, PET allows for excellent depiction of specific metabolic activity, molecules and receptors in vivo. Besides the established ${ }^{18}$ F-fluordesoxyglucose (FDG), a broad spectrum of PET tracers is under development for the non-invasive imaging of cellular processes such as angiogenesis, proliferation and hypoxia (Table 1). DOTA-TATE has been shown to be a valuable tracer for sensitive imaging of somatostatin-receptor expression in neuroendocrine tumors and meningioma delineation $[115,116]$. SPECT resembles PET in its application of radioactive tracers and the detection of gamma rays for image acquisition. However, in SPECT the gamma radiation emitted by the tracer is directly measured, whereas in PET positrons emitted by the applied tracers annihilate with surrounding electrons, causing two gamma photons to be emitted in $180^{\circ}$ directions. PET scanners detect photon emissions coincident in time, thereby providing more spatial information of the observed
Table 1 Novel PET tracers for research and patient care beyond ${ }^{18}$ F-fluor-desoxyglucose ( ${ }^{18}$ F-FDG) aim at molecular targets such as integrins and somatostatin receptors or a sensitive for up-regulated amino acid turnover or cell membrane synthesis of tumor cells

\begin{tabular}{|c|c|c|c|}
\hline Nuclide & Tracer & Metabolism & Comment \\
\hline \multirow{10}{*}{${ }^{11} \mathrm{C}$} & ${ }^{11} \mathrm{C}$ - Methionine & Amino acid & \multirow{4}{*}{$\begin{array}{l}\text { Increased amino } \\
\text { acid uptake and } \\
\text { turnover of tumor } \\
\text { cells }\end{array}$} \\
\hline & ${ }^{11} \mathrm{C}$-Tyrosine & Amino acid & \\
\hline & ${ }^{11} \mathrm{C}$ - Leucine & Amino acid & \\
\hline & ${ }^{18} \mathrm{~F}$ - Fluoruracile & Amino acid & \\
\hline & $\begin{array}{l}{ }^{18} \mathrm{~F} \text { - Fluorethyltyrosine } \\
\left({ }^{18} \mathrm{~F}-\mathrm{FET}\right)\end{array}$ & $\begin{array}{l}\text { Amino acid } \\
\text { derivative }\end{array}$ & \multirow{14}{*}{$\begin{array}{l}\text { Longer half-life of } \\
{ }^{18} \mathrm{~F} \text { allows for ap- } \\
\text { plication of tracers } \\
\text { in imaging centers } \\
\text { without cyclotron }\end{array}$} \\
\hline & ${ }^{18} \mathrm{~F}$ - Fluordesoxyglucose & Glucose & \\
\hline & $\left({ }^{18} \mathrm{~F}-\mathrm{FDG}\right)$ & metabolism & \\
\hline & ${ }^{18} \mathrm{~F}-$ & Hypoxia & \\
\hline & Fluorazomyzinarabinoside & & \\
\hline & $\left({ }^{18} F-F A Z A\right)$ & & \\
\hline \multirow{8}{*}{${ }^{18} \mathrm{~F}$} & ${ }^{18} \mathrm{~F}$ - Fluoromisonidazole & Hypoxia & \\
\hline & $\left({ }^{18} \mathrm{~F}-\mathrm{FMISO}\right)$ & & \\
\hline & ${ }^{18} \mathrm{~F}$ - Fluorthymidine & Proliferation & \\
\hline & $\left({ }^{18} \mathrm{~F}-\mathrm{FLT}\right)$ & & \\
\hline & ${ }^{18} \mathrm{~F}$ - Galacto-RGD & $a_{v} \beta_{3}$-Integrins & \\
\hline & $\begin{array}{l}{\left[{ }^{18} \text { F-Arg-Gly-Asp (RGD) }\right.} \\
\text { Peptide] }\end{array}$ & & \\
\hline & ${ }^{18} \mathrm{~F}$ - Choline & $\begin{array}{l}\text { Prostate } \\
\text { carcinoma }\end{array}$ & \\
\hline & ${ }^{18} \mathrm{~F}$ - Fluoride & $\begin{array}{l}\text { Bone } \\
\text { metabolism }\end{array}$ & \\
\hline${ }^{68} \mathrm{Ga}$ & $\begin{array}{l}{ }^{68} \mathrm{Ga} \text {-DOTATOC/DOTA- } \\
\text { TATE }\end{array}$ & $\begin{array}{l}\text { Somatostatin } \\
\text { receptors } \\
\text { (SSR) }\end{array}$ & $\begin{array}{l}\text { SSR-overexpressing } \\
\text { tumors }\end{array}$ \\
\hline
\end{tabular}

radiation event and, thus, higher image resolution. Different radiotracers can be applied in SPECT for functional imaging of the brain $\left({ }^{99 \mathrm{~m}} \mathrm{Tc}-(\mathrm{HMPAO})\right.$ hexamethylpropylene amine oxime), the myocardium ( ${ }^{99 \mathrm{~m}}$ Tc-tetrofosmin, ${ }^{99 \mathrm{~m}} \mathrm{Tc}$-sestamibi), malignant $\left({ }^{123} \mathrm{I}-\right.$ (MIBG) metaiodobenzylguanidine), or inflammatory processes $\left({ }^{99 \mathrm{~m}} \mathrm{Tc}\right.$ or ${ }^{111} \mathrm{In}$ - in vivo labeled leukocytes). However, both functional molecular imaging techniques provide only limited spatial resolution and require complementary morphologic imaging for anatomic mapping and morphologic correlation.

In morphologic imaging, particularly tomographic modalities such as CT and MRI underwent tremendous innovation during the last 15 years currently providing excellent spatial resolution, 3D imaging and increasingly also functional information from tissue perfusion and diffusion. To combine morphological and functional/molecular information in diagnostic decision making, hybrid imaging with $\mathrm{PET} / \mathrm{CT}$ has entered clinical routine in oncologic imaging using mostly ${ }^{18}$ F-fluordesoxyglucose (FDG) for cancer 
diagnosis, as predictive imaging biomarker [117], for monitoring of therapy response and radiotherapy planning [118-120]. As a highly sensitive imaging modality based on molecular biology, PET has the ability to assess functional and molecular processes in benign and malignant tissues, which are altered in the earliest stages of virtually all diseases, before morphological changes occur. It compares normal and abnormal tissues on a functional rather than morphological level as MRI and CT. Functional and molecular imaging techniques such as ${ }^{18}$ F-FDG-PET/CT can be applied to define a metabolically active biological tumor volume (BTV) for radiation therapy planning [121,122], still limited by its lack of spatial resolution and relatively low specificity to reliably delineate the tumor as accurately as required by precision RT techniques like intensitymodulated radiotherapy (IMRT). ${ }^{18}$ F-FDG-PET/CT has the potential to safely decrease radiotherapy volumes by better delineation of tumor and better lymph node detection $[123,124]$ and may be used as predictive/prognostic marker [125,126]. It enables radiation dose escalation [127], and experimentally permits the definition of regions in heterogeneous tumor at greatest risk of recurrence, thus facilitating the redistribution of radiation doses within the tumor to focus on these regions - a principle which is called dose-painting by contours (DPBC) [128]. Another method of specific dose escalation in a PET-positive area is dose painting by numbers (DPBN), where an inhomogeneous radiation dose distribution is intended on a voxel-byvoxel base [129]. Recent developments in PET reconstruction focusing on time-of-flight (TOF) and point spread function (PSF) modeling bear the potential for further improvements in diagnostic performance, as shown by Schaefferkoetter and colleagues [130]. They investigated four different reconstruction schemes on real tumor patient images and found that the application of TOF and PSF modeling may help to optimize particularly the detection of small, lowintensity, focal disease in larger patients.

However, FDG is not a tumor-specific tracer and accumulation in benign lesions, such as regions of inflammation, causes false-positive results with consecutively low specificity [131]. Therefore, novel alternative tracers with higher specificity are under investigation (Table 1), including radiolabeled amino acids for monitoring protein synthesis and radiolabeled choline for monitoring cell membrane synthesis, which may allow for a dedicated characterization of the tumor microenvironment on a molecular level prior to as well as during RT and especially useful in radiotherapy planning, e.g. in high-risk prostate cancer [132]. The amino acid methionine has been used for grading, prognostication and tumor extent delineation for RT planning and showed promising results in the detection and delineation of viable tumors particularly in low-grade gliomas [133]. In clinical practice however, ${ }^{18}$ F-labeled PET molecules have revealed advantages compared to those that are ${ }^{11} \mathrm{C}$-labeled due to a longer physical half-life of $110 \mathrm{~min}$ vs. $20 \mathrm{~min}$. In this regard, ${ }^{18}$ F-labeled $\mathrm{O}-(2)$ fluoroethyl-L-tyrosine $\left(\left[{ }^{18} \mathrm{~F}\right]\right.$-FET) is one of the most widely used amino acid tracers [134]. Available data suggests that for RT planning the additional use of $\left[{ }^{18} \mathrm{~F}\right]$-FET-PET to conventional imaging might improve gross tumor volume delineation [135,136]. For PET-based imaging of tumor hypoxia, tracers such as ${ }^{18} \mathrm{~F}$-fluoromisonidazole $\left({ }^{18} \mathrm{~F}\right.$ FMISO) and ${ }^{124}$ I-iodoazomycin galactopyranoside $\left({ }^{124} \mathrm{I}\right.$ IAZG) were investigated by Riedl and colleagues in rats bearing liver tumors with peritoneal metastasis by dynamic microPET imaging. The authors demonstrated that ${ }^{18}$ F-FMISO and ${ }^{124}$ I-IAZG localized the same tumor regions to be hypoxic, however with superior diagnostic quality of ${ }^{18}$ F-FMISO images in the investigated Morris hepatoma model due to higher count statistics of ${ }^{18}$ F-FMISO. Clinically, Thorwarth and colleagues investigated reoxygenation dynamics and its relationship to local control after radiotherapy in a small group of head-and-neck cancer patients $(n=10)$, based on repeated dynamic ${ }^{18}$ F-FMISO PET examinations. The authors reported that a tumor control probability model was developed based on repeated ${ }^{18} \mathrm{~F}$-FMISO PET scans during RT to estimate reoxygenation time which may be applicable for hypoxia image-guided dose escalation in RT [137].

Recently, first hybrid MRI/PET scanners have been installed for patient care combining the excellent soft tissue contrast of MRI with the options of PET in functional and molecular imaging. Compared to CT, MRI provides superior soft tissue contrast together with options for perfusion, diffusion and spectroscopic imaging, as complementing functional parameters, without the use of ionizing radiation $[50,138]$. The combination of both imaging modalities therefore provides strong synergies for imaging physiological and pathophysiological processes in vivo following multiparametric morphological, functional and molecular imaging concepts in oncology, neurology and cardiology.

Accurate delineation of gross tumor volume is a prerequisite for a successful treatment of cancer with radiotherapy. FDG-PET plays an increasingly important role in radiotherapy that goes beyond staging and selection of patients. For some tumors, such as NSCLC, FDG-PET has led to the safe decrease of radiotherapy volumes, enabling radiation dose escalation and redistribution of radiation doses within the tumor (tumor heterogeneity), along with a significant role in monitoring radiotherapy response. In esophageal cancer and bronchial cancer, FDG-PET/CT has gained significant predictive importance in multimodal treatment settings particularly before, during and after neo-adjuvant radiochemotherapy and is very helpful in target volume 
delineation $[139,140]$. Currently, besides for staging/restaging purposes, $\mathrm{PET} / \mathrm{CT}$ is playing a complementary role to other modalities such as CT and MRI for target volume delineation in radiotherapy. Standardized protocols should be established to better define what role $\mathrm{PET}$ and/or PET/CT scans should play in radiotherapy planning.

\section{Conclusions}

Advances in the understanding of the pathophysiology of cancer have triggered profound developments in multimodality treatment concepts comprising surgery, radiotherapy and molecularly targeted anti-cancer agents. These novel concepts of personalized cancer therapy require careful pre-treatment stratification and timely and efficient therapy monitoring to maximize patient benefit on an individual basis. Therefore, different functional and molecular imaging methods with corresponding biomarkers are currently being developed and characterized pre-clinically with the perspective of clinical translation. Molecularly tailored adaption of MRI, CT, ultrasound, PET/CT (-MRI) and optical imaging modalities represent promising approaches for the demands of targeted combination therapy in radiation oncology.

\section{Competing interests}

The authors declare that they have no competing interests.

\section{Authors' contributions}

CC: review concept, literature research and manuscript drafting, MRI and CT section. PMP: literature research and manuscript drafting ultrasound section. ME: literature research and manuscript drafting, Optical Imaging section. DAC: literature research and manuscript drafting, ultrasound section. CR: literature research and manuscript drafting, PET section. KN: literature research and manuscript drafting, MRI and CT section. KL: review concept, literature research and manuscript drafting. FW: review concept, literature research and manuscript drafting. DH: review concept, literature research and manuscript drafting. MFR: review concept and manuscript drafting. CB: review concept, literature research and manuscript drafting. MN: review concept, literature research and manuscript drafting. All authors read and approved the final manuscript

\section{Author details \\ 'Department of Clinical Radiology, Laboratory of Experimental Radiology, University of Munich Hospitals, Campus Großhadern, Marchioninistraße 15, 81377 Munich, Germany. ${ }^{2}$ Department of Radiation Oncology, University of Munich Hospitals, Campus Großhadern, Marchioninistraße 15, 81377 Munich, Germany. ${ }^{3}$ IZKF Core Unit OPTI, Department of Radiology, University Hospital Muenster, Albert-Schweitzer-Campus 1, Muenster, Germany. ${ }^{4}$ Comprehensive Cancer Imaging Centre, Division of Imaging Sciences \& Biomedical Engineering, King's College London, The Rayne Institute, 4th Floor Lambeth Wing, St. Thomas Hospital, London SE1 7EH, UK. ${ }^{5}$ Department of Radiation Oncology, University Medical Centre Mannheim, University of Heidelberg, Theodor-Kutzer-Ufer 1-3, Mannheim 68167, Germany. ${ }^{6}$ Institute of Clinical Radiology and Nuclear Medicine, University Medical Center Mannheim, Medical Faculty Mannheim, Heidelberg University, Mannheim, Germany.}

Received: 17 June 2013 Accepted: 20 December 2013

Published: 3 January 2014

\section{References}

1. Hanahan D, Weinberg RA: Hallmarks of cancer: the next generation. Cell 2011, 144:646-674.
2. Van Elmpt W, Pottgen C, De Ruysscher D: Therapy response assessment in radiotherapy of lung cancer. Q J Nucl Med Mol Imaging 2011, 55:648-654.

3. Humm JL, Dewhirst MW, Bhujwalla ZM: Introduction to the special issue on molecular imaging in radiation biology. Radiat Res 2012, 177:329-330.

4. Mangoni M, Vozenin MC, Biti G, Deutsch E: Normal tissues toxicities triggered by combined anti-angiogenic and radiation therapies: hurdles might be ahead. Br J Cancer 2012, 107(2):308-314.

5. Winkelmann CT, Figueroa SD, Sieckman GL, Rold TL, Hoffman TJ: Noninvasive MicroCT imaging characterization and in vivo targeting of $\mathrm{BB} 2$ receptor expression of a PC-3 bone metastasis model. Mol Imaging Biol 2012, 14(6):667-675.

6. Boll H, Nittka S, Doyon F, Neumaier M, Marx A, Kramer M, Groden C, Brockmann MA: Micro-CT based experimental liver imaging using a nanoparticulate contrast agent: a longitudinal study in mice. PLoS One 2011, 6:e25692.

7. Cyran CC, von Einem JC, Paprottka PM, Schwarz B, Ingrisch M, Dietrich O, Hinkel R, Bruns CJ, Clevert DA, Eschbach R, et al: Dynamic contrastenhanced computed tomography imaging biomarkers correlated with immunohistochemistry for monitoring the effects of sorafenib on experimental prostate carcinomas. Invest Radiol 2012, 47:49-57.

8. Lazanyi KS, Abramyuk A, Wolf G, Tokalov S, Zophel K, Appold S, Herrmann T, Baumann M, Abolmaali N: Usefulness of dynamic contrast enhanced computed tomography in patients with non-small-cell lung cancer scheduled for radiation therapy. Lung Cancer 2010, 70(3):280-285.

9. Miles KA: Perfusion $\mathrm{CT}$ for the assessment of tumour vascularity: which protocol? Br J Radiol 2003, 76(1):S36-S42.

10. Miles KA, Charnsangavej C, Lee FT, Fishman EK, Horton K, Lee TY: Application of $\mathrm{CT}$ in the investigation of angiogenesis in oncology. Acad Radiol 2000, 7:840-850.

11. Miles KA, Griffiths MR: Perfusion CT: a worthwhile enhancement? Br J Radiol 2003, 76:220-231.

12. Tateishi U, Kusumoto M, Nishihara H, Nagashima K, Morikawa T, Moriyama $\mathrm{N}$ : Contrast-enhanced dynamic computed tomography for the evaluation of tumor angiogenesis in patients with lung carcinoma. Cancer 2002, 95:835-842.

13. Lind JS, Meijerink MR, Dingemans AM, van Kuijk C, Ollers MC, de Ruysscher $D$, Postmus PE, Smit EF: Dynamic contrast-enhanced CT in patients treated with sorafenib and erlotinib for non-small cell lung cancer: a new method of monitoring treatment? Eur Radiol 2010, 20:2890-2898.

14. Petralia G, Bonello L, Viotti S, Preda L, D'Andrea G, Bellomi M: CT perfusion in oncology: how to do it. Cancer Imaging 2010, 10:8-19.

15. Hermans R, Meijerink M, Van den Bogaert W, Rijnders A, Weltens C, Lambin $P$ : Tumor perfusion rate determined noninvasively by dynamic computed tomography predicts outcome in head-and-neck cancer after radiotherapy. Int J Radiat Oncol Biol Phys 2003, 57:1351-1356.

16. Zhang LJ, Zhao YE, Wu SY, Yeh BM, Zhou CS, Hu XB, Hu QJ, Lu GM: Pulmonary embolism detection with dual-energy CT: experimental study of dual-source CT in rabbits. Radiology 2009, 252:61-70.

17. Zhang LJ, Yang GF, Zhao YE, Zhou CS, Lu GM: Detection of pulmonary embolism using dual-energy computed tomography and correlation with cardiovascular measurements: a preliminary study. Acta Radiol 2009, 50:892-901.

18. Zhang $L$, Wu S, Wang $M$, Lu L, Chen B, Jin L, Wang J, Larson AC, Lu GM: Quantitative dual energy CT measurements in rabbit VX2 liver tumors: Comparison to perfusion CT measurements and histopathological findings. Eur J Radiol 2012, 81:1766-1775.

19. Giusti S, Buccianti P, Castagna M, Fruzzetti E, Fattori S, Castelluccio E, Caramella D, Bartolozzi C: Preoperative rectal cancer staging with phasedarray MR. Radiat Oncol 2012, 7:29.

20. Champ CE, Siglin J, Mishra MV, Shen X, Werner-Wasik M, Andrews DW, Mayekar SU, Liu H, Shi W: Evaluating changes in radiation treatment volumes from post-operative to same-day planning MRI in High-grade gliomas. Radiat Oncol 2012, 7:220.

21. Cyran CC, Paprottka PM, Schwarz B, Sourbron S, Ingrisch M, von Einem J, Pietsch H, Dietrich O, Hinkel R, Bruns CJ, et al: Perfusion MRI for monitoring the effect of sorafenib on experimental prostate carcinoma: a validation study. AJR Am J Roentgenol 2012, 198:384-391.

22. Henzler T, Konstandin S, Schmid-Bindert G, Apfaltrer P, Haneder S, Wenz F, Schad L, Manegold C, Schoenberg SO, Fink C: Imaging of tumor viability in lung cancer: initial results using 23Na-MRI. Fortschr Geb Rontgenstr Nuklearmed 2012, 184:340-344. 
23. Bottomley PA: Spatial localization in NMR spectroscopy in vivo. Ann N Y Acad Sci 1987, 508:333-348.

24. Frahm J, Michaelis T, Merboldt KD, Hanicke W, Gyngell ML, Chien D, Bruhn $\mathrm{H}$ : Localized NMR spectroscopy in vivo. Progress and problems. NMR Biomed 1989, 2:188-195

25. Robbins ME, Brunso-Bechtold JK, Peiffer AM, Tsien Cl, Bailey JE, Marks LB: Imaging Radiation-Induced Normal Tissue Injury. Radiat Res 2012, 177(4):449-466.

26. Sundgren $P C$, Cao Y: Brain irradiation: effects on normal brain parenchyma and radiation injury. Neuroimaging Clin N Am 2009, 19:657-668

27. Pasantes-Morales $\mathrm{H}$, Franco $\mathrm{R}$, Torres-Marquez ME, Hernandez-Fonseca K, Ortega A: Amino acid osmolytes in regulatory volume decrease and isovolumetric regulation in brain cells: contribution and mechanisms. Cell Physiol Biochem 2000, 10:361-370.

28. Majos C, Alonso J, Aguilera C, Serrallonga M, Acebes JJ, Arus C, Gili J: Adult primitive neuroectodermal tumor: proton MR spectroscopic findings with possible application for differential diagnosis. Radiology 2002, 225:556-566.

29. Stadlbauer A, Gruber S, Nimsky C, Fahlbusch R, Hammen T, Buslei R, Tomandl B, Moser E, Ganslandt O: Preoperative grading of gliomas by using metabolite quantification with high-spatial-resolution proton MR spectroscopic imaging. Radiology 2006, 238:958-969.

30. Kuroda K, Suzuki Y, Ishihara Y, Okamoto K: Temperature mapping using water proton chemical shift obtained with 3D-MRSI: feasibility in vivo. Magn Reson Med 1996, 35:20-29.

31. Fonteyne V, Villeirs G, Speleers B, De Neve W, De Wagter C, Lumen N, De Meerleer G: Intensity-modulated radiotherapy as primary therapy for prostate cancer: report on acute toxicity after dose escalation with simultaneous integrated boost to intraprostatic lesion. Int J Radiat Oncol Biol Phys 2008, 72:799-807.

32. Roe K, Mikalsen LT, van der Kogel AJ, Bussink J, Lyng H, Ree AH, Marignol L, Olsen DR: Vascular responses to radiotherapy and androgen-deprivation therapy in experimental prostate cancer. Radiat Oncol 2012, 7:75.

33. Sourbron S: Technical aspects of MR perfusion. Eur J Radio/ 2010, 76:304-313.

34. Franiel T, Hamm B, Hricak H: Dynamic contrast-enhanced magnetic resonance imaging and pharmacokinetic models in prostate cancer. Eur Radiol 2011, 21:616-626.

35. Nguyen $\mathrm{VL}$, Kooi ME, Backes WH, van Hoof RH, Saris AE, Wishaupt MC, Hellenthal FA, van der Geest RJ, Kessels AG, Schurink GW, Leiner T: Suitability of pharmacokinetic models for dynamic contrast-enhanced MRI of abdominal aortic aneurysm vessel wall: a comparison. PLoS One 2013, 8:e75173.

36. Turkheimer FE, Hinz R, Cunningham VJ: On the undecidability among kinetic models: from model selection to model averaging. J Cereb Blood Flow Metab 2003, 23:490-498

37. Rischke HC, Schafer AO, Nestle U, Volegova-Neher N, Henne K, Benz MR, Schultze-Seemann W, Langer M, Grosu AL: Detection of local recurrent prostate cancer after radical prostatectomy in terms of salvage radiotherapy using dynamic contrast enhanced-MRI without endorectal coil. Radiat Oncol 2012, 7:185.

38. Roe K, Kakar M, Seierstad T, Ree AH, Olsen DR: Early prediction of response to radiotherapy and androgen-deprivation therapy in prostate cancer by repeated functional MRI: a preclinical study. Radiat Oncol 2011, 6:65.

39. Bloch BN, Furman-Haran E, Helbich TH, Lenkinski RE, Degani H, Kratzik C, Susani M, Haitel A, Jaromi S, Ngo L, Rofsky NM: Prostate cancer: accurate determination of extracapsular extension with high-spatial-resolution dynamic contrast-enhanced and T2-weighted MR imaging-initial results. Radiology 2007, 245:176-185.

40. Fung SH, Roccatagliata L, Gonzalez RG, Schaefer PW: MR Diffusion Imaging in Ischemic Stroke. Neuroimaging Clin N Am 2011, 21:345-377.

41. Choi SH, Paeng JC, Sohn CH, Pagsisihan JR, Kim YJ, Kim KG, Jang JY, Yun TJ, $\mathrm{Kim} \mathrm{JH}$, Han MH, Chang KH: Correlation of 18F-FDG uptake with apparent diffusion coefficient ratio measured on standard and high $b$ value diffusion MRI in head and neck cancer. J Nucl Med 2011, 18(9):2579-2584.

42. Inglese $M$, Bester M: Diffusion imaging in multiple sclerosis: research and clinical implications. NMR Biomed 2010, 23:865-872.

43. Wybranski C, Zeile M, Lowenthal D, Fischbach F, Pech M, Rohl FW, Gademann G, Ricke J, Dudeck O: Value of diffusion weighted MR imaging as an early surrogate parameter for evaluation of tumor response to high-dose-rate brachytherapy of colorectal liver metastases. Radiat Oncol 2011, 6:43.

44. Ueno Y, Kitajima K, Sugimura K, Kawakami F, Miyake H, Obara M, Takahashi S: Ultra-high b-value diffusion-weighted MRI for the detection of prostate cancer with 3-T MRI. JMR 2013, 38(1):154-160.

45. Blackledge MD, Leach MO, Collins DJ, Koh DM: Computed diffusionweighted MR imaging may improve tumor detection. Radiology 2011, 261:573-581.

46. Koh DM, Collins DJ, Orton MR: Intravoxel incoherent motion in body diffusion-weighted MRI: reality and challenges. AJR Am J Roentgenol 2011, 196:1351-1361.

47. Notohamiprodjo M, Staehler M, Steiner N, Schwab F, Sourbron SP, Michaely HJ, Helck AD, Reiser MF, Nikolaou K: Combined diffusion-weighted, blood oxygen level-dependent, and dynamic contrast-enhanced MRI for characterization and differentiation of renal cell carcinoma. Acad Radiol 2013, 20:685-693.

48. Barentsz JO, Richenberg J, Clements R, Choyke P, Verma S, Villeirs G, Rouviere O, Logager V, Futterer JJ, European Society of Urogenital R: ESUR prostate MR guidelines 2012. Eur Radiol 2012, 22:746-757.

49. Bumb A, Regino CA, Perkins MR, Bernardo M, Ogawa M, Fugger L, Choyke PL, Dobson PJ, Brechbiel MW: Preparation and characterization of a magnetic and optical dual-modality molecular probe. Nanotechnology 2010, 21:175704.

50. Makowski MR, Wiethoff AJ, Blume U, Cuello F, Warley A, Jansen CH, Nagel E, Razavi R, Onthank DC, Cesati RR, et al: Assessment of atherosclerotic plaque burden with an elastin-specific magnetic resonance contrast agent. Nat Med 2011, 17:383-388.

51. Serres S, Soto MS, Hamilton A, McAteer MA, Carbonell WS, Robson MD, Ansorge O, Khrapitchev A, Bristow C, Balathasan L, et al: Molecular MRI enables early and sensitive detection of brain metastases. Proc Natl Acad Sci USA 2012, 109:6674-6679.

52. Westmeyer $G G$, Durocher $Y$, Jasanoff $A$ : A secreted enzyme reporter system for MRI. Angew Chem Int Ed Engl 2010, 49:3909-3911.

53. Bowers CR, Weitekamp DP: Transformation of symmetrization order to nuclear-spin magnetization by chemical reaction and nuclear magnetic resonance. Phys Rev Lett 1986, 57:2645-2648.

54. Olsson LE, Chai CM, Axelsson O, Karlsson M, Golman K, Petersson JS: MR coronary angiography in pigs with intraarterial injections of a hyperpolarized 13C substance. Magn Reson Med 2006, 55:731-737.

55. Svensson J, Mansson S, Johansson E, Petersson JS, Olsson LE: Hyperpolarized 13C MR angiography using trueFISP. Magn Reson Med 2003, 50:256-262

56. Day SE, Kettunen MI, Gallagher FA, Hu DE, Lerche M, Wolber J, Golman K, Ardenkjaer-Larsen $\mathrm{JH}$, Brindle KM: Detecting tumor response to treatment using hyperpolarized $13 \mathrm{C}$ magnetic resonance imaging and spectroscopy. Nat Med 2007, 13:1382-1387.

57. Kurhanewicz J, Vigneron DB, Brindle K, Chekmenev EY, Comment A, Cunningham CH, Deberardinis RJ, Green GG, Leach MO, Rajan SS, et al: Analysis of cancer metabolism by imaging hyperpolarized nuclei: prospects for translation to clinical research. Neoplasia 2011, 13:81-97.

58. Chaumeil MM, Ozawa T, Park I, Scott K, James CD, Nelson SJ, Ronen SM: Hyperpolarized 13C MR spectroscopic imaging can be used to monitor Everolimus treatment in vivo in an orthotopic rodent model of glioblastoma. Neuroimage 2012, 59:193-201.

59. Day SE, Kettunen MI, Cherukuri MK, Mitchell JB, Lizak MJ, Morris HD, Matsumoto S, Koretsky AP, Brindle KM: Detecting response of rat C6 glioma tumors to radiotherapy using hyperpolarized [1-13C] pyruvate and $13 \mathrm{C}$ magnetic resonance spectroscopic imaging. Magn Reson Med 2011, 65:557-563.

60. Golman K, Zandt RI, Lerche M, Pehrson R, Ardenkjaer-Larsen JH: Metabolic imaging by hyperpolarized $13 \mathrm{C}$ magnetic resonance imaging for in vivo tumor diagnosis. Cancer Res 2006, 66:10855-10860.

61. Mansson S, Johansson E, Magnusson P, Chai CM, Hansson G, Petersson JS, Stahlberg F, Golman K: 13C imaging-a new diagnostic platform. Eur Radiol 2006, 16:57-67.

62. Golman K, Olsson LE, Axelsson O, Mansson S, Karlsson M, Petersson JS: Molecular imaging using hyperpolarized 13C. Br J Radiol 2003, 76(2):S118-S127.

63. Paprottka PM, Cyran CC, Zengel P, von Einem J, Wintersperger B, Nikolaou $K$, Reiser MF, Clevert DA: Non-invasive contrast enhanced ultrasound for quantitative assessment of tumor microcirculation. Contrast mixed 
mode examination vs. Only contrast enhanced ultrasound examination Clin Hemorheol Microcirc 2010, 46:149-158.

64. Willmann JK, Paulmurugan R, Chen K, Gheysens O, Rodriguez-Porcel M, Lutz AM, Chen IY, Chen X, Gambhir SS: US imaging of tumor angiogenesis with microbubbles targeted to vascular endothelial growth factor receptor type 2 in mice. Radiology 2008, 246:508-518.

65. Rychak JJ, Graba J, Cheung AM, Mystry BS, Lindner JR, Kerbel RS, Foster FS: Microultrasound molecular imaging of vascular endothelial growth factor receptor 2 in a mouse model of tumor angiogenesis. Mol Imaging 2007, 6:289-296.

66. Lee DJ, Lyshchik A, Huamani J, Hallahan DE, Fleischer AC: Relationship between retention of a vascular endothelial growth factor receptor 2 (VEGFR2)targeted ultrasonographic contrast agent and the level of VEGFR2 expression in an in vivo breast cancer model. J Ultrasound Med 2008, 27:855-866.

67. Anderson CR, Rychak JJ, Backer M, Backer J, Ley K, Klibanov AL: scVEGF microbubble ultrasound contrast agents: a novel probe for ultrasound molecular imaging of tumor angiogenesis. Invest Radiol 2010, 45:579-585.

68. Jun HY, Park SH, Kim HS, Yoon KH: Long residence time of ultrasound microbubbles targeted to integrin in murine tumor model. Acad Radiol 2010, 17:54-60.

69. Crouzet S, Murat FJ, Pommier P, Poissonnier L, Pasticier G, Rouviere O, Chapelon JY, Rabilloud M, Belot A, Mege-Lechevallier F, et al: Locally recurrent prostate cancer after initial radiation therapy: early salvage high-intensity focused ultrasound improves oncologic outcomes. Radiother Oncol 2012, 105:198-202.

70. Anderson CR, Hu X, Zhang H, Tlaxca J, Decleves AE, Houghtaling R, Sharma K, Lawrence M, Ferrara KW, Rychak JJ: Ultrasound molecular imaging of tumor angiogenesis with an integrin targeted microbubble contrast agent. Invest Radiol 2011, 46:215-224.

71. Robinson D, Liu D, Steciw S, Field C, Daly H, Saibishkumar EP, Fallone G, Parliament M, Amanie J: An evaluation of the Clarity 3D ultrasound system for prostate localization. J App/ Clin Med Phys 2012, 13:3753.

72. Guckenberger M, Richter A, Boda-Heggemann J, Lohr F: Motion compensation in radiotherapy. Crit Rev Biomed Eng 2012, 40:187-197.

73. Greis C: Summary of technical principles of contrast sonography and future perspectives. Radiologe 2011, 51:456-461.

74. Greis C: Ultrasound contrast agents as markers of vascularity and microcirculation. Clin Hemorheol Microcirc 2009, 43:1-9.

75. Clevert DA, Sommer WH, Helck A, Reiser M: Duplex and contrast enhanced ultrasound (CEUS) in evaluation of in-stent restenosis after carotid stenting. Clin Hemorheol Microcirc 2011, 48:199-208.

76. Clevert DA, Minaifar N, Kopp R, Stickel M, Meimarakis G, Sommer W, Reiser $\mathrm{M}$ : Imaging of endoleaks after endovascular aneurysm repair (EVAR) with contrast-enhanced ultrasound (CEUS). a pictorial comparison with CTA. Clin Hemorheol Microcirc 2009, 41:151-168.

77. Helck A, Sommer WH, Wessely M, Notohamiprodjo M, Reiser M, Clevert DA Benefit of contrast enhanced ultrasound for detection of ischaemic lesions and arterio venous fistulas in renal transplants - a feasibility study. Clin Hemorheol Microcirc 2011, 48:149-160.

78. Clevert DA, Sommer WH, Helck A, Saam T, Reiser M: Improved carotid atherosclerotic plaques imaging with contrast-enhanced ultrasound (CEUS). Clin Hemorheol Microcirc 2011, 48:141-148.

79. Clevert DA, Helck A, Paprottka PM, Schwarz F, Reiser MF: [Latest developments in ultrasound of the liver]. Radiologe 2011, 51:661-670.

80. Zengel P, Schrotzlmair F, Kramer M, Paprottka P, Clevert DA: [Management of salivary gland diseases with contrast-enhanced ultrasound]. Radiologe 2011, 51:490-496.

81. Clevert DA, Helck A, Paprottka PM, Reiser MF, Jung EM: [Contrast-enhanced ultrasound imaging of the carotid artery]. Radiologe 2011, 51:483-489.

82. Jung EM, Uller W, Stroszczynski C, Clevert DA: Contrast-enhanced sonography. Therapy control of radiofrequency ablation and transarterial chemoembolization of hepatocellular carcinoma. Radiologe 2011, 51:462-468

83. Schwarz F, Sommer WH, Reiser M, Clevert DA: [Contrast-enhanced sonography for blunt force abdominal trauma]. Radiologe 2011, 51:475-482

84. Paprottka PM, Zengel P, Ingrisch M, Cyran CC, Eichhorn M, Reiser MF, Nikolaou K, Clevert DA: [Contrast-enhanced ultrasound in animal models]. Radiologe 2011, 51:506-513.

85. Stieger SM, Bloch SH, Foreman O, Wisner ER, Ferrara KW, Dayton PA: Ultrasound assessment of angiogenesis in a matrigel model in rats. Ultrasound Med Biol 2006, 32:673-681.
86. Lassau N, Chami L, Chebil M, Benatsou B, Bidault S, Girard E, Abboud G, Roche A: Dynamic contrast-enhanced ultrasonography (DCE-US) and anti-angiogenic treatments. Discov Med 2011, 11:18-24.

87. Pieters B, Wijkstra H, van Herk M, Kuipers R, Kaljouw E, de la Rosette J, Koning C: Contrast-enhanced ultrasound as support for prostate brachytherapy treatment planning. J Contemp Brachytherapy 2012, 4:69-74.

88. Krix M, Plathow C, Essig M, Herfarth K, Debus J, Kauczor HU, Delorme S: Monitoring of liver metastases after stereotactic radiotherapy using lowMI contrast-enhanced ultrasound-initial results. Eur Radiol 2005, 15:677-684.

89. Greis C: Quantitative evaluation of microvascular blood flow by contrastenhanced ultrasound (CEUS). Clin Hemorheol Microcirc 2011, 49:137-149.

90. Korpanty G, Carbon JG, Grayburn PA, Fleming JB, Brekken RA: Monitoring response to anticancer therapy by targeting microbubbles to tumor vasculature. Clin Cancer Res 2007, 13:323-330.

91. Weller GE, Wong MK, Modzelewski RA, Lu E, Klibanov AL, Wagner WR, Villanueva FS: Ultrasonic imaging of tumor angiogenesis using contrast microbubbles targeted via the tumor-binding peptide arginine-arginineleucine. Cancer Res 2005, 65:533-539.

92. Xuan JW, Bygrave M, Valiyeva F, Moussa M, Izawa JI, Bauman GS, Klibanov A Wang F, Greenberg NM, Fenster A: Molecular targeted enhanced ultrasound imaging of flk1 reveals diagnosis and prognosis potential in a genetically engineered mouse prostate cancer model. Mol Imaging 2009, 8:209-220.

93. Kiessling F, Fokong S, Koczera P, Lederle W, Lammers T: Ultrasound microbubbles for molecular diagnosis, therapy, and theranostics. J Nucl Med 2012, 53:345-348

94. Ophir J, Cespedes I, Ponnekanti H, Yazdi Y, Li X: Elastography: a quantitative method for imaging the elasticity of biological tissues. Ultrason Imaging 1991, 13:111-134.

95. De Zordo T, Chhem R, Smekal V, Feuchtner G, Reindl M, Fink C, Faschingbauer R, Jaschke W, Klauser AS: Real-time sonoelastography: findings in patients with symptomatic achilles tendons and comparison to healthy volunteers. Ultraschall Med 2010, 31:394-400.

96. Krouskop TA, Wheeler TM, Kallel F, Garra BS, Hall T: Elastic moduli of breast and prostate tissues under compression. Ultrason Imaging 1998, 20:260-274.

97. Itoh A, Ueno E, Tohno E, Kamma H, Takahashi H, Shiina T, Yamakawa M, Matsumura T: Breast disease: clinical application of US elastography for diagnosis. Radiology 2006, 239:341-350.

98. Lorenz A, Ermert H, Sommerfeld HJ, Garcia-Schurmann M, Senge T, Philippou S: Ultrasound elastography of the prostate. A new technique for tumor detection. Ultraschall Med 2000, 21:8-15.

99. Van Vledder MG, Boctor EM, Assumpcao LR, Rivaz H, Foroughi P, Hager GD, Hamper UM, Pawlik TM, Choti MA: Intra-operative ultrasound elasticity imaging for monitoring of hepatic tumour thermal ablation. HPB (Oxford) 2010, 12:717-723.

100. Zhang D, Zhang S, Wan M, Wang S: A fast tissue stiffness-dependent elastography for HIFU-induced lesions inspection. Ultrasonics 2011 51:857-869.

101. Chenot J, Melodelima D, N'Djin WA, Souchon R, Rivoire M, Chapelon $J Y$ : Intra-operative ultrasound hand-held strain imaging for the visualization of ablations produced in the liver with a toroidal HIFU transducer: first in vivo results. Phys Med Biol 2010, 55:3131-3144.

102. Cui LG, Shao JH, Wang JR, Bai J, Zhang YZ: Ultrasound elastography of ethanol-induced hepatic lesions: in vitro study. Chin Med Sci J 2009, 24:81-85.

103. Hoyt K, Forsberg F, Merritt CR, Liu JB, Ophir J: In vivo elastographic investigation of ethanol-induced hepatic lesions. Ultrasound Med Biol 2005, 31:607-612.

104. Adriaenssens N, Belsack D, Buyl R, Ruggiero L, Breucq C, De Mey J, Lievens P, Lamote J: Ultrasound elastography as an objective diagnostic measurement tool for lymphoedema of the treated breast in breast cancer patients following breast conserving surgery and radiotherapy. Radiol Oncol 2012 46:284-295.

105. Luker GD, Luker KE: Optical imaging: current applications and future directions. J Nucl Med 2008, 49:1-4

106. Valentini G, D'Andrea C, Ferrari R, Pifferi A, Cubeddu R, Martinelli M, Natoli C, Ubezio P, Giavazzi R: In vivo measurement of vascular modulation in 
experimental tumors using a fluorescent contrast agent. Photochem Photobiol 2008, 84:1249-1256.

107. Park JK, Jang SJ, Kang SW, Park S, Hwang SG, Kim WJ, Kang JH, Um HD: Establishment of animal model for the analysis of cancer cell metastasis during radiotherapy. Radiat Oncol 2012, 7:153

108. Li W, Li F, Huang Q, Frederick B, Bao S, Li CY: Noninvasive imaging and quantification of epidermal growth factor receptor kinase activation in vivo. Cancer Res 2008, 68:4990-4997.

109. Wolf F, Li W, Li F, Li CY: Non-invasive, quantitative monitoring of hyperthermia-induced EGFR activation in xenograft tumours. Int $J$ Hyperthermia 2011, 27:427-434

110. Li W, Li F, Huang Q, Shen J, Wolf F, He Y, Liu X, Hu YA, Bedford JS, Li CY: Quantitative, noninvasive imaging of radiation-induced DNA doublestrand breaks in vivo. Cancer Res 2011, 71:4130-4137.

111. Backer MV, Gaynutdinov TI, Patel V, Bandyopadhyaya AK, Thirumamagal BT, Tjarks W, Barth RF, Claffey K, Backer JM: Vascular endothelial growth factor selectively targets boronated dendrimers to tumor vasculature. Mol Cancer Ther 2005, 4:1423-1429.

112. Deliolanis N, Lasser T, Hyde D, Soubret A, Ripoll J, Ntziachristos V: Freespace fluorescence molecular tomography utilizing 360 degrees geometry projections. Opt Lett 2007, 32:382-384.

113. Ntziachristos $V$, Tung $\mathrm{CH}$, Bremer C, Weissleder R: Fluorescence molecular tomography resolves protease activity in vivo. Nat Med 2002, 8:757-760.

114. Zavattini G, Vecchi S, Mitchell G, Weisser U, Leahy RM, Pichler BJ, Smith DJ, Cherry SR: A hyperspectral fluorescence system for 3D in vivo optical imaging. Phys Med Biol 2006, 51:2029-2043.

115. Gehler B, Paulsen F, Oksuz MO, Hauser TK, Eschmann SM, Bares R, Pfannenberg C, Bamberg M, Bartenstein P, Belka C, Ganswindt U: [68Ga]DOTATOC-PET/CT for meningioma IMRT treatment planning. Radiat Oncol 2009, 4:56.

116. Combs SE, Ganswindt U, Foote RL, Kondziolka D, Tonn JC: State-of-the-art treatment alternatives for base of skull meningiomas: complementing and controversial indications for neurosurgery, stereotactic and robotic based radiosurgery or modern fractionated radiation techniques. Radiat Oncol 2012, 7:226.

117. Goldberg N, Kundel Y, Purim O, Bernstine H, Gordon N, Morgenstern S, Idelevich E, Wasserberg N, Sulkes A, Groshar D, Brenner B: Early prediction of histopathological response of rectal tumors after one week of preoperative radiochemotherapy using 18 F-FDG PET-CT imaging. A prospective clinical study. Radiat Oncol 2012, 7:124.

118. Zhu A, Lee D, Shim H: Metabolic positron emission tomography imaging in cancer detection and therapy response. Semin Oncol 2011, 38:55-69.

119. Ford EC, Herman J, Yorke E, Wahl RL: 18 F-FDG PET/CT for image-guided and intensity-modulated radiotherapy. J NuCl Med 2009, 50:1655-1665.

120. MacDonald SL, Mulroy L, Wilke DR, Burrell S: PET/CT aids the staging of and radiotherapy planning for early-stage extranodal natural killer/T-cell lymphoma, nasal type: a case series. Radiat Oncol 2011, 6:182.

121. Ling CC, Humm J, Larson S, Amols H, Fuks Z, Leibel S, Koutcher JA: Towards multidimensional radiotherapy (MD-CRT): biological imaging and biological conformality. Int J Radiat Oncol Biol Phys 2000, 47:551-560.

122. Vees H, Casanova N, Zilli T, Imperiano H, Ratib O, Popowski Y, Wang H, Zaidi $\mathrm{H}$, Miralbell R: Impact of 18 F-FDG PET/CT on target volume delineation in recurrent or residual gynaecologic carcinoma. Radiat Oncol 2012, 7:176.

123. Tsai CS, Lai CH, Chang TC, Yen TC, Ng KK, Hsueh S, Lee SP, Hong JH: A prospective randomized trial to study the impact of pretreatment FDGPET for cervical cancer patients with MRI-detected positive pelvic but negative para-aortic lymphadenopathy. Int J Radiat Oncol Biol Phys 2010, 76:477-484.

124. Mai SK, Welzel G, Hermann B, Wenz F, Haberkorn U, Dinter DJ: Can the radiation dose to CT-enlarged but FDG-PET-negative inguinal lymph nodes in anal cancer be reduced? Sonderb Strahlenther Onkol 2009, 185:254-259.

125. Massaccesi M, Calcagni ML, Spitilli MG, Cocciolillo F, Pelligro F, Bonomo L, Valentini V, Giordano A: (1)(8)F-FDG PET-CT during chemo-radiotherapy in patients with non-small cell lung cancer: the early metabolic response correlates with the delivered radiation dose. Radiat Oncol 2012, 7:106.

126. Parlak C, Topkan E, Onal C, Reyhan M, Selek U: Prognostic value of gross tumor volume delineated by FDG-PET-CT based radiotherapy treatment planning in patients with locally advanced pancreatic cancer treated with chemoradiotherapy. Radiat Oncol 2012, 7:37.
127. Wurschmidt F, Petersen C, Wahl A, Dahle J, Kretschmer M: [18 F] fluoroethylcholine-PET/CT imaging for radiation treatment planning of recurrent and primary prostate cancer with dose escalation to PET/CTpositive lymph nodes. Radiat Oncol 2011, 6:44.

128. Thorwarth D, Geets X, Paiusco M: Physical radiotherapy treatment planning based on functional PET/CT data. Radiother Oncol 2010, 96:317-324

129. Rickhey M, Moravek Z, Eilles C, Koelbl O, Bogner L: 18F-FET-PET-based dose painting by numbers with protons. Strahlenther Onkol 2010, 186:320-326.

130. Schaefferkoetter J, Casey M, Townsend D, El Fakhri G: Clinical impact of time-of-flight and point response modeling in PET reconstructions: a lesion detection study. Phys Med Biol 2013, 58:1465-1478.

131. Strauss LG: Fluorine-18 deoxyglucose and false-positive results: a major problem in the diagnostics of oncological patients. Eur J NuCl Med 1996, 23:1409-1415.

132. Vees H, Steiner C, Dipasquale G, Chouiter A, Zilli T, Velazquez M, Namy S, Ratib O, Buchegger F, Miralbell R: Target volume definition in high-risk prostate cancer patients using sentinel node SPECT/CT and 18 F-choline PET/CT. Radiat Oncol 2012, 7:134

133. Jacobs AH, Thomas A, Kracht LW, Li H, Dittmar C, Garlip G, Galldiks N, Klein JC, Sobesky J, Hilker R, et al: 18 F-fluoro-L-thymidine and 11Cmethylmethionine as markers of increased transport and proliferation in brain tumors. J Nucl Med 2005, 46:1948-1958.

134. Walter F, la Fougere C, Belka C, Niyazi M: Technical Issues of [(18)F]FET-PET Imaging for Radiation Therapy Planning in Malignant Glioma Patients A Review. Frontiers Oncol 2012, 2:130.

135. Niyazi M, Geisler J, Siefert A, Schwarz SB, Ganswindt U, Garny S, Schnell O, Suchorska B, Kreth FW, Tonn JC, et al: FET-PET for malignant glioma treatment planning. Radiother Oncol 2011, 99:44-48.

136. Weber DC, Zilli T, Buchegger F, Casanova N, Haller G, Rouzaud M, Nouet $P$, Dipasquale G, Ratib O, Zaidi H, et al: [(18)F]Fluoroethyltyrosine- positron emission tomography-guided radiotherapy for high-grade glioma. Radiat Oncol 2008, 3:44.

137. Thorwarth D, Eschmann SM, Paulsen F, Alber M: A model of reoxygenation dynamics of head-and-neck tumors based on serial 18 F-fluoromisonidazole positron emission tomography investigations. Int J Radiat Oncol Biol Phys 2007, 68:515-521.

138. Kim MJ: Current limitations and potential breakthroughs for the early diagnosis of hepatocellular carcinoma. Gut Liver 2011, 5:15-21.

139. De Ruysscher D, Wanders S, van Haren E, Hochstenbag M, Geeraedts W, Utama I, Simons J, Dohmen J, Rhami A, Buell U, et al: Selective mediastinal node irradiation based on FDG-PET scan data in patients with nonsmall-cell lung cancer: a prospective clinical study. Int J Radiat Oncol Biol Phys 2005, 62:988-994.

140. Brucher BL, Weber W, Bauer M, Fink U, Avril N, Stein HJ, Werner M, Zimmerman F, Siewert JR, Schwaiger M: Neoadjuvant therapy of esophageal squamous cell carcinoma: response evaluation by positron emission tomography. Ann Surg 2001, 233:300-309.

doi:10.1186/1748-717X-9-3

Cite this article as: Cyran et al.: Visualization, imaging and new preclinical diagnostics in radiation oncology. Radiation Oncology 2014 9:3.

\section{Submit your next manuscript to BioMed Central and take full advantage of:}

- Convenient online submission

- Thorough peer review

- No space constraints or color figure charges

- Immediate publication on acceptance

- Inclusion in PubMed, CAS, Scopus and Google Scholar

- Research which is freely available for redistribution 